\title{
Removal of FD\&C Red No.40 Food Dye from an Aqueous Solution by Vine-Trimming Waste
}

\author{
Hale Sütcü
}

\begin{abstract}
The purpose of this study is to examine the removal of the food dye FD\&C Red No.40 from an aqueous solution by means of vine-trimming waste. The adsorption experiments focused on the parameters such as contact time, $\mathrm{pH}$ of the aqueous solution, the amount of adsorbent, initial dye concentration and the temperature of the aqueous solution. Moreover, a study was carried out to make sure that the adsorption was in compliance with the Langmuir and Freundlich isotherm models and thermodynamic parameters were determined.
\end{abstract}

Index Terms - Vine-trimming waste, food dye, adsorption.

\section{INTRODUCTION}

Issues such as consumer awareness and expectations of variety, increasing market share and requirements for national and international standards make it necessary to use additives in the food industry. Of these additives, food dyes are referred to as substances that impart or restore colour to foods and contain natural food components and natural resources that are not generally consumed as they are directly and that are not used as the characteristic components of foods as well as peparations that are produced through the selective extraction of pigments in such a way that they do not contain other nutrient and aromatic constituents that are physically and/or chemically extracted from food substances and other renewable natural resources [1].

$7 \times 10^{5}$ tons of over 100 types of food dyes are produced worldwide that are aimed at the textile, food, paper, plastic and other sectors [2]. However, large losses and waste from the production and use of these dyes prove detrimental to the human health and environment.

In general, four different methods, namely chemical, physical, biological and radiation-electrical-acoustic methods, are employed for treating wastes that contain food dyes [3]. These include a large variety of methods such as flocculation, precipitation, filtration, flotation, membrane filtration, ozonization, oxidation, ion exchange, coagulation and adsorption that are used in various industries [3]-[7]. Of these methods, adsorption stands out as a more advantageous method compared to the others for treating industrial waste water as it is economical and takes into account environmental concerns. There are not many studies that deal with the adsorption of food dyes using various adsorbents. The existing ones deal with the adsorption of acid blue 9 and

Manuscript received December 20, 2013; revised March 4, 2014.

H. Sütcü is with the Food Engineering Department, Bülent Ecevit University, Zonguldak, 67100, Turkey (e-mail: halesutcu@ hotmail.com, hale.sutcu@beun.edu.tr). food yellow 3 using chitosan [8], [9], the adsorption of sunset yellow dyes on CaAl-LDH- $-\mathrm{NO}_{3}$ [10], the adsorption of FD\&D Red No.40 by means of chitosan [11]-[14], the adsorption of Brilliant Blue food dye with hen feathers [15], the adsorption of Tartrazine, Allura Red, Sunset Yellow and Indigo Carmine food dyes on Lewatit MonoPlus M-600 [16] and tartrazine allura red adsorption over Spirulina platensis [17].

FD\&C Red No.40 is a food dye that belongs to the azo dyes group and bears the names of Allura red, E129, Food Red 17 and C.I. 16035. It is dark red in colour, water-soluble and derived from coal [18]. This food dye is used in fruit juices and powdered beverages, bakery products, dairy products, chewing gums and sweets, meat and fish products, canned food, fruits and vegetables, deserts, soups, sauces, pharmaceutics and cosmetic products.

This study deals with the adsorption of FD\&C Red No.40 food dye from an aqueous solution using wine-trimming wastes.

\section{EXPERIMENTAL}

\section{A. Materials}

The food dye FD\&C Red No.40, which was bought from a local firm, has a purity of $85 \%$.

The vine-trimming waste samples selected as adsorbent were dried at a temperature of $105^{\circ} \mathrm{C}$ for $24 \mathrm{~h}$ and reduced to the testing sizes in the range of $0,250-0,840 \mathrm{~mm}$. The chemical analysis of the samples was performed in accordance with ASTM standards and the results are given in Table I.

TABLE I: CHEMICAL ANALYSIS RESULTS OF THE VINE-TRIMMING WASTE

\begin{tabular}{|l|l|l|l|l|l|}
\hline Ash $^{\mathrm{a}}$ & $\mathrm{VM}^{\mathrm{a}}$ & $\mathrm{FC}^{\mathrm{a}}$ & $\mathrm{C}^{\mathrm{b}}$ & $\mathrm{H}^{\mathrm{b}}$ & $\mathrm{N}^{\mathrm{b}}$ \\
\hline 2,51 & 79,42 & 18,07 & 46,23 & 5,98 & 1,11 \\
\hline
\end{tabular}

a, on dry basis , \%

$\mathrm{b}$, on dry and ash free basis, $\%$

\section{B. Method}

Stock solutions were prepared which had a dye concentration of $1 \mathrm{~g} / \mathrm{L}$. The adsorption experiments were conducted in a water bath at a stirring rate of $150 \mathrm{rpm}$. The $\mathrm{pH}$ of the aqueous solution was adjusted using the solutions $\mathrm{O}, 1 \mathrm{~N}$ $\mathrm{HCl}$ and $0,1 \mathrm{~N} \mathrm{NaOH}$. Following the adsorption experiments, the dye solution was filtered and the maximum dye absorbances in the filtrate were measured at the maximum wave length $(500 \mathrm{~nm})$ in a PG Instrument model $\mathrm{Uv}$-Vis spectrophotometer. In addition, the Langmuir and Freundlich 
adsorption isotherms were applied and the thermodynamic parameters calculated.

The variables that were used during the experiments are contact time $(5,10,20,40,60,90,120$ and $180 \mathrm{~min}$.$) , \mathrm{pH}$ of the aqueous solution $(2,3,4,5,6,7$, and 8$)$, the amount of adsorbent (100, 250, 500, 750, 1000, 1500 and $2000 \mathrm{mg} / \mathrm{L})$, initial dye concentration $(50,75,100,200,300,400$ and 750 $\mathrm{mg} / \mathrm{L})$ and the temperature of the aqueous solution $(25,45$ and $\left.65^{\circ} \mathrm{C}\right)$.

\section{Adsorption Isotherm Models}

Adsorption isotherms were applied to the data obtained from the experiments which involved the adsorption of aqueous solutions having an initial dye concentrations of 50 , $75,100,200,300,400$ and $750 \mathrm{mg} / \mathrm{L}$ at the solution temperatures of 25,45 and $65^{\circ} \mathrm{C}$.

The Langmuir isotherm is expressed by the following equation:

$$
C_{e} / q_{e}=1 / Q_{\max } \times b+C_{e} / Q_{\max }
$$

where $C_{e}$ denotes equilibrium dye concentration $(\mathrm{mg} / \mathrm{L}), q_{e}$ the amount of dye adsorbed per unit mass of the equilibrium adsorbent (mg/g), $Q_{\max }$ adsorption capacity $(\mathrm{mg} / \mathrm{g}$ ) and b the Langmuir constant $(\mathrm{L} / \mathrm{mg})$. The slope of the line obtained by plotting a graph of $C_{e} / q_{e}$ against $C_{e}$ yields the value $1 / Q_{\max }$ and the point of intersection gives the value of $1 / Q_{\max } \times b$ [19].

Moreover, since the Langmuir isotherm assumes that adsorption takes place in a single layer, the separation factor $R_{L}$ indicates the type of the isotherm.

$$
R_{L}=1 / 1+b \times C_{0}
$$

where $b$ indicates the Langmuir constant $(\mathrm{L} / \mathrm{mg})$ and $C_{0}$ initial concentration (mg/L) [20], [21].

The value of $R_{L}>1$ indicates that the isotherm is unsuitable. If the value is 1 , it is indicative of a linear isotherm. In the case of a value in the range of $0-1$, the isotherm is considered to be suitable. If the value is 0 , it denotes that the isotherm is irreversible.

According to the Freundlich isotherm is expressed as:

$$
\log q_{e}=\log K_{F}+(1 / n) \log C_{e}
$$

where $q_{e}$ represents the amount of dye adsorbed per unit mass of the equilibrium adsorbent $(\mathrm{mg} / \mathrm{g}), C_{e}$ equilibrium dye concentration $(\mathrm{mg} / \mathrm{L}), K_{F}$ adsorption capacity $(\mathrm{mg} / \mathrm{g})$ and $\mathrm{n}$ adsorption intensity. The slope of the line obtained by drawing a graph of the $\log q_{e}$ value versus the $\log C_{e}$ value yields $1 / \mathrm{n}$ and the point of intersection gives the $\log K_{F}$ value [22].

The thermodynamic parameters such as Gibbs free energy, enthalpy and entropy that are released during the adsorption process were calculated using the following equations:

$$
\begin{gathered}
\Delta G^{\mathrm{o}}=-R T \ln K_{c} \\
\ln K_{c}=-\Delta H^{\mathrm{o}} / R T+\Delta S^{\mathrm{o}} / R \\
K_{c}=C_{a d} / C_{e}
\end{gathered}
$$

where $\Delta G^{\mathrm{o}}$ denotes standard Gibbs free energy, $\Delta H^{\mathrm{o}}$ standard enthalpy, $\Delta S^{\mathrm{o}}$ standard entropy, $K_{c}$ adsorption equilibrium constant, $C_{a d}$ dye concentration during the adsorption process $(\mathrm{mg} / \mathrm{L}), C_{e}$ the concentration of dye that remained unadsorbed in the solution $(\mathrm{mg} / \mathrm{L}), R$ gas constant $(8,314 \mathrm{j} / \mathrm{molK})$ and $T$ solution temperature $(K)$. The slope and point of intersection in the graph of $\ln \mathrm{Kc}$ versus $1 / \mathrm{T}$ help calculate $\Delta H^{\mathrm{o}}$ and $\Delta S^{\mathrm{o}}$ [23], [24].

\section{RESULTS AND DISCUSSION}

\section{A. The Effect of Experimental Parameters on Adsorption}

The effect of contact time on adsorption is illustrated in Fig. 1. The increase in the adsorption percentage with increasing time indicates that the adsorption time affects adsorption capacity. When adsorption time was increased from 5 min to $180 \mathrm{~min}$, the adsorption yield rose from $\% 27$ to $\% 97,15$. The optimum adsorption time was determined to be 60 minutes.

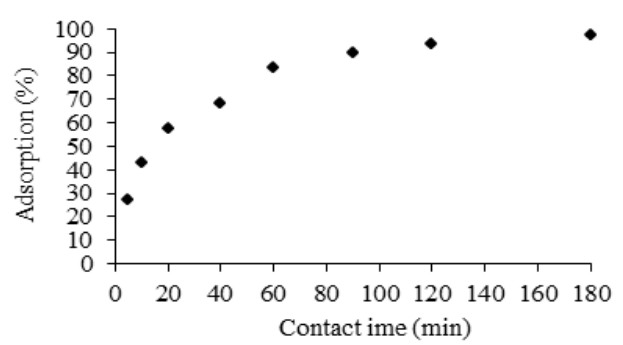

Fig. 1. The effect of contact time on adsorption. (Vine-trimming waste: $1 \mathrm{~g} / \mathrm{L}$, pH:6, FD\&C Red No.40:100 mg/L, temperature: $25^{\circ} \mathrm{C}$ ).

Fig. 2 illustrates the effect of $\mathrm{pH}$ on adsorption. When the $\mathrm{pH}$ value was increased up to 6 , the adsorption yield rose to as high as $83.6 \%$ and above this value, it was found to decrease. It was established that the $\mathrm{pH}$ of the solution where adsorption occurred had an effect on the adsorption percentage. The optimal $\mathrm{pH}$ value was determined to be 6 .

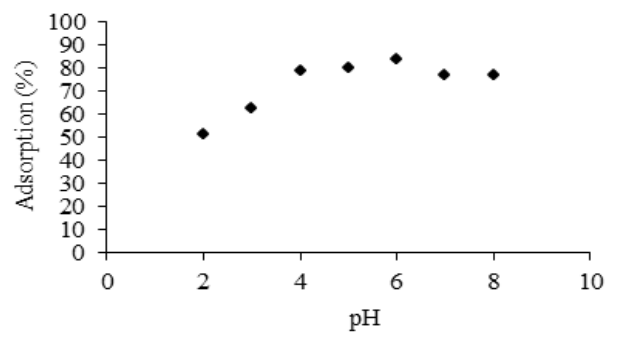

Fig. 2. The effect of $\mathrm{pH}$ on adsorption (Vine-trimming waste: $1 \mathrm{~g} / \mathrm{L}, \mathrm{FD} \& \mathrm{C}$ Red No.40:100 mg/L, temperature: $25{ }^{\circ} \mathrm{C}$, time: $60 \mathrm{~min}$ ).

Fig. 3 shows the effect of varying amounts of adsorbent on adsorption. As the amount of vine-trimming waste was increased, there was an increase in the adsorption percentage as well. The optimal amount of adsorbent was determined to be $1 \mathrm{~g} / \mathrm{L}$.

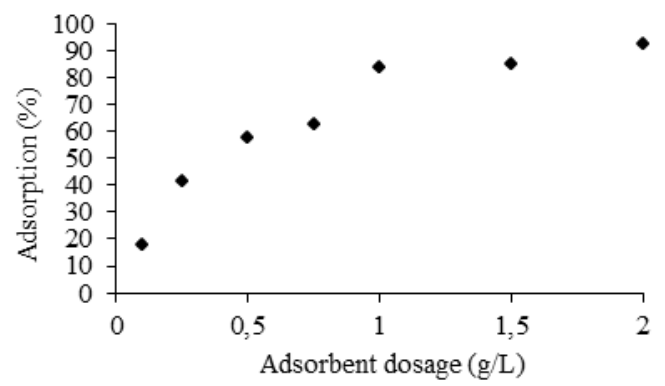

Fig. 3. The effect of the amount of vine-trimming waste on adsorption (FD\&C Red No.40:100 mg/L, temperature: $25^{\circ} \mathrm{C}$, pH:6, time:60 min). 
Fig. 4 illustrates the effect of initial dye concentration at different temperatures 25,45 and $65^{\circ} \mathrm{C}$ on adsorption. It was determined that as initial dye concentration at all the three temperatures was increased, there was a decrease in the adsorption yield. It was found that with increasing temperature the adsorption percentage decreased. It was also established that temperature has an effect on adsorption capacity. The most suitable temperature was determined to be $25^{\circ} \mathrm{C}$.

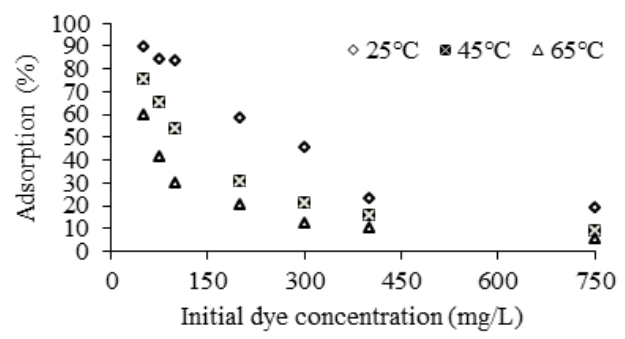

Fig. 4. The effect of initial dye concentration at different temperatures on adsorption (Vine-trimming waste: $1 \mathrm{~g} / \mathrm{L}, \mathrm{pH}: 6$, time:60 min).

\section{B. Adsorption Isotherms}

The Langmuir and Freundlich isotherms were applied to the values in Fig. 4 and the values calculated are given in Table II and Table III.

TABLE II: LANGMUIR ISOTHERM CONSTANTS

\begin{tabular}{|c|c|c|c|}
\hline $\begin{array}{c}\text { Temperature } \\
\left({ }^{\circ} \mathrm{C}\right)\end{array}$ & $\begin{array}{c}Q_{\max } \\
(\mathrm{mg} / \mathrm{g})\end{array}$ & $\begin{array}{c}b \\
(\mathrm{~L} / \mathrm{mg})\end{array}$ & $R^{2}$ \\
\hline 25 & 135,14 & 0,044 & 0,9411 \\
\hline 45 & 66,23 & 0,082 & 0,9992 \\
\hline 65 & 42,55 & 0,055 & 0,9974 \\
\hline
\end{tabular}

It was found that, according to the Langmuir isotherm model, as the temperature of the aqueous solution is increased, adsorption capacity decreases.

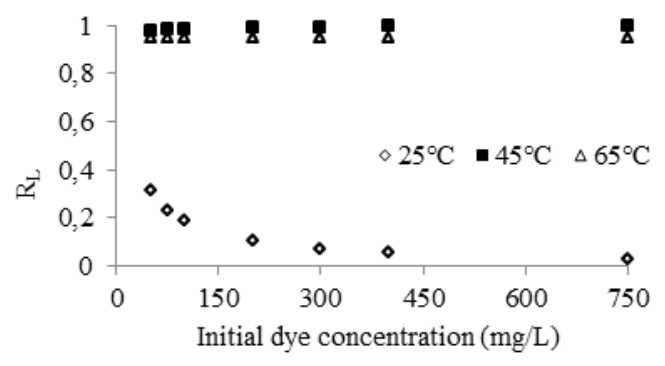

Fig. 5. The effect of initial dye concentration on the $R_{L}$ value.

Fig. 5 gives the effect of initial dye concentration on the RL value. The fact that the $R_{L}$ values are in the range of 0-1 indicates that adsorption is suitable and vine-trimming waste is suitable for the adsorption of the food dye FD\&C Red No.40.

TABLE III: FREUNDLICH ISOTHERM CONSTANTS

\begin{tabular}{|c|c|c|c|}
\hline $\begin{array}{c}\text { Temperature } \\
\left({ }^{\circ} \mathrm{C}\right)\end{array}$ & $\begin{array}{c}K_{F} \\
(\mathrm{mg} / \mathrm{g})\end{array}$ & $n$ & $R^{2}$ \\
\hline 25 & 39,1 & 4,88 & 0,7580 \\
\hline 45 & 30,7 & 7,92 & 0,8636 \\
\hline 65 & 20,61 & 8,93 & 0,8241 \\
\hline
\end{tabular}

It was determined that, according to the Freundlich isotherm model as well, with increasing aqueous solution temperature adsorption capacity decreases.

Since the correlation value of the Langmuir isotherm model was established to be higher than that of the Freundlich isotherm model, adsorption by means of vine-trimming waste can be said to be suited to the Langmuir isotherm.

Table IV gives the thermodynamic parameters that were calculated as a function of temperature. The fact that the value for the Gibbs free energy was found to be negative indicates that adsorption takes place on its own. As for the enthalpy value, if it proves to be negative, this indicates that adsorption occurs in an exothermic manner.

TABLE IV: THERMODYNAMIC PARAMETERS

\begin{tabular}{|c|c|c|c|}
\hline $\begin{array}{c}\text { Temperature } \\
\left({ }^{\circ} \mathrm{C}\right)\end{array}$ & $\begin{array}{c}\Delta G^{\circ} \\
(\mathrm{J} / \mathrm{molK})\end{array}$ & $\begin{array}{c}\Delta H^{\circ} \\
(\mathrm{KJ} / \mathrm{molK})\end{array}$ & $\begin{array}{c}\Delta S^{\circ} \\
(\mathrm{J} / \mathrm{molK})\end{array}$ \\
\hline 25 & $-4320,81$ & & \\
\hline 45 & $-1626,46$ & $-40,75$ & $-122,50$ \\
\hline 65 & $-557,67$ & & \\
\hline
\end{tabular}

\section{CONCLUSION}

This study makes it clear that vine-trimming waste that cannot be utilized for economic purposes can be used for the removal of the food dye FD\&C Red No.40 from an aqueous solution. It was established that adsorption by means of vine-trimming waste is affected by such variables as $\mathrm{pH}$ of the aqueous solution, the amount of adsorbent, initial dye concentration and solution temperature. The optimal adsorption parameters were determined to be $1 \mathrm{~g} / \mathrm{L}$ of vine-trimming waste, the food dye FD\&C Red No.40 with a concentration of $100 \mathrm{mg} / \mathrm{L}$, an aqueous solution with a $\mathrm{pH}$ of 6 , a solution temperature of $25^{\circ} \mathrm{C}$ and a time period of $60 \mathrm{~min}$. Langmuir adsorption isotherm model was determined to be more appropriate.

\section{REFERENCES}

[1] Türk Glda Kodeksi Gıda Katkı Maddeleri Yönetmeliği (in Turkish), Resmi Gazete, number: 28693, 30 June 2013.

[2] S. L. Wang, Y. C. Chen, Y. H. Yen, and T. W. Liang, "Utilisation of chitinous materials in pigment adsorption," Food Chemistry, vol. 135, issue 3, pp. 1134-1140, December 2012.

[3] V. K. Gupta and Suhas, "Application of low-cost adsorbents for dye removal-A review," Journal of Environmental Management, vol. 90, issue 8, pp. 2313-2342, June 2009.

[4] G. Crini and P. M. Badot, "Application of chitosan, a natural aminopolysaccharide, for dye removal from aqueous solutions by adsorption processes using batch studies: a review of recent literature," Progress in Polymer Sciences, vol. 33, issue 4, pp. 399-447, April 2008.

[5] D. F. Martin, R. J. Alessio, and C. H. Mccane, "Removal of synthetic food dyes in aqueous solution by Octolig," Journal of Environmental Science and Health, Part A:Toxic/Hazardous Substances and Environmental Engineering, vol. 48, issue 5, pp. 495-500, 2013.

[6] H. Y. Xue, F. Han, and B. Y. He, "Biosorption of food dye onto gelatin microspheres:Equilibrium isotherm and thermodyanamic analysis," Advanced Materials Research, vol. 476-478, pp. 2239-2242, 2012.

[7] G. L. Dotto, E. C. Lima, and L. A. A. Pinto, "Biosorption of food dyes onto Spirulina platensis nanoparticles:Equilibrium isotherm and thermodynamic analysis," Bioresource Technology, vol. 103, issue 1, pp. 123-130, January 2012.

[8] G. L. Dotto and L. A. A. Pinto, "Adsorption of food dyes acid blue 9 and food yellow 3 onto chitosan:Stirring rate effect in kinetics and mechanism," Journal of Hazardous Materials, vol. 187, issue 1-3, pp. 164-170, March 2011.

[9] G. L. Dotto and L. A. A. Pinto, "Adsorption of food dyes onto chitosan:Optimization process and kinetic," Carbohydrate Polymers, vol. 84, issue 1, pp. 231-238, February 2011. 
[10] F. Pereira de Sá, B. N. Cunha, and L. M. Nunes, "Effect of pH on the adsorption of sunset yellow FCF food dye into a layered double hydroxide (CaAl-LDH-NO $\left.{ }_{3}\right)$," Chemical Engineering Journal, vol. 215-216, pp. 122-127, January 2013.

[11] R. G. Sánchez-Duarte, D. I. Sánchez-Machado, J. López-Cervantes, and Ma. A. Correa-Murrieta, "Adsorption of allura red dye by cross-linked chitosan from shrimp waste," Water Science and Technology, vol. 65, issue 4, pp. 618-623, 2012.

[12] J. S. Piccin, G. L. Dotto, M. L. G. Vieira, and L. A. A. Pinto, "Kinetics and mechanism of the food dye FD\&C Red 40 adsorption onto chitosan," Journal of Chemical\&Engineering Data, vol. 56, issue 10, pp. 3759-3765, 2011.

[13] J. S. Piccin, G. L. Dotto, and L. A. A. Pinto, "Adsorption isotherms and thermochemical data of FD\&C Red No 40 binding by chitosan," Brazilian Journal of Chemical Engineering, vol. 28, issue 2, pp. 295-304, April-June 2011.

[14] J. S. Piccin, M. L. G. Vieira, J. O. Gonçalves, G. L. Dotto, and L. A. A. Pinto, "Adsorption of FD\&C Red No.40 by chitosan: Isotherms analysis," Journal of Food Engineering, vol. 95, issue 1, pp. 16-20, November 2009.

[15] A. Mittal, "Use of hen feathers as potential adsorbent for the removal of a hazardous dye, brilliant blue FCF, from waste water," Journal of Hazardous Materials, vol. 128, issue 2-3, pp. 233-239, February 2006.

[16] M. Wawrzkiewicz and Z. Hubicki, "Kinetic studies of dyes sorption from aqeous solutions onto the strongly basic anion-exchanger Lewatit MonoPlus M-600," Chemical Engineering Journal, vol. 150, issue 2-3, pp. 509-515, August 2009.

[17] G. L. Dotto, M. L. G. Vieira, V. M. Esquerdo, and L. A. A. Pinto, "Equilibrium and thermodynamics of azo dyes biosorption onto Spirulina platensis," Brazilian Journal of Chemical Engineering, vol. 30, issue 1, pp. 13-21, January-March 2013.
[18] Allura Red AC, From Wikipedia. [Online]. Available: http://en.wikipedia.org/wiki/Allura_Red_AC

[19] I. Langmuir, "The constitution and fundamental properties of solids and liquids," Journal of the American Chemical Society, vol. 38, issue 11, pp. 2221-2295, 1916.

[20] C. Namasivayam and D. Kavitha, "Removal of Congo Red from water by adsorption onto activated carbon prepared from coir pith, an agricultural solid waste," Dyes and Pigments, vol. 54, issue 1, pp. 47-58, July 2002.

[21] M. Basibuyuk, and C. F. Forster, "An examination of adsorption characteristics of basic dye (Maxilon Red BL-N) on to live activated sludge system," Process Biochemistry, vol. 38, issue 9, pp. 1311-1316, April 2003.

[22] H. Freundlich, "Über die adsorption in lösungen," Zeitschrift Für Physikalische Chemie A, vol. 57, pp. 385-470, 1906.

[23] M. Dakiky, M. Khamis, A. Manassra, and M. Mer'eb, "Selective adsorption of chromium (VI) in industrial wastewater using low-cost abundantly available adsorbents," Advances in Environmental Research, vol. 6, issue 4, pp. 533- 540, October 2002.

[24] H. Nollet, M. Roels, P. Lutgen, P. Van Der Meeren, and W. Verstraete, "Removal of PCBs from wastewater using fly ash," Chemosphere, vol. 53, issue 6, pp. 655-665, November 2003.

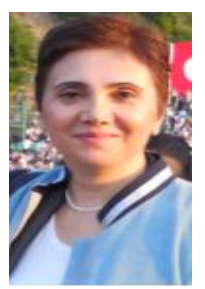

H. Sütcï is an associate professor and the head of the Food Engineering Department at Bülent Ecevit University, Turkey. She received her Ph.D., MSc. and BSc. degree in chemical engineering from Yildiz Technical University, Turkey. Her research is related to energy tecnologies (pyrolysis, biooil, biogas) and chemical technologies (activated carbon, biomass, evaluation of food waste, adsorption, determination of heavy metals and mineral matters in food, adsorption). 